\title{
Efficacy of Betel Leaf Extracts as Antioxidant in Moisturizing Cream
}

\author{
Pornpimol Muangthai, Patcharapun Ditsayamontri, Nutchanard Tumtamai and Thanawan Uaroon \\ Department of Chemistry, Faculty of Science, Srinakharinwirot University, Sukhumvit 23, Bangkok 10110, Thailand
}

\begin{abstract}
This work aims to study the appropriate method for extract Betel leaf as crude extracts to prepare as a natural antioxidant in moisturizing hand cream. Betel leaf was treated by 7 methods and the optimized method was selected for preparation of Betel leaf extract. The fresh Betel leaf and dried Betel leaf were used in this study. Betel leaf extracts were analysed for total phenolic content and essential oil as eugenol content. Then Betel leaf extracts were used as the one component for moisturizing hand cream. The lipid oxidation was evaluated by measurement on malondialdehyde content. The results revealed that an extracts solution from dried Betel leaf contained total phenolic content and eugenol content more than fresh Betel leaf. The ethanol extraction method was the optimum method since this method showed the maximum total phenolic content and eugenol content in dried Betel leaf as $5.26 \mathrm{~g} / 100 \mathrm{~g}$ and $138.95 \mathrm{mg} / 100 \mathrm{~g}$, respectively. The moisturizing creams were formulated by using crude Betel leaf extracts as the one composition compare with base cream (no addition of Betel leaf extracts). The moisturizing cream samples were analysed for malondialdehyde. its showed that the cream that contained Betel leaf extract contained malondialdehyde content lower than in cream base. Thus, crude extracts from Betel leaf showed the efficacy to reduce lipid oxidation reaction in moisturizing hand cream.
\end{abstract}

Key words: Betel leaf, eugenol, lipid oxidation, malondialdehyde, total phenolic content.

\section{Background/Objectives and Goals}

Betel is a plant and its leaf is famous for chewing betel nut [1]. It is also the traditional plant in Asian countries such as India, Sri Lanka, Malaysia, Philippines and also Thailand [2]. Its leaf exhibits as traditional herbs that can be used for wound healing, gastro-protective, and hepato-protective activities [3]. Betel leaf contained many phytochemical compounds that effectively scavenge reactive oxygen species including superoxide anions and hydroxyl radicals as other free radicals [4]. In general phytochemicals compound reveal many health benefits such as disease-fighting, stress-defeating, disease-combating, and conferring health benefits [5]. The other important substance found in Betel leaf is eugenol which was known as an essential oil [6], as showed in Fig. 1.

Eugenol (4-allyl-2-methoxyphenol) is a semi-volatile compound and a major source from

Corresponding author: Pornpimol Muangthai, Ph.D., associate professor, research fields: analytical chemistry, applied chemistry. clove, basil, cinnamon, fennel, marjoram, nutmeg and anise [7]. It possesses as an antioxidant, anti-inflammatory and anti-fungal [8]. Eugenol has been widely used as herbal drug and also used as an important flavoring agent in cosmetic and food products [9]. It possesses as an antioxidant, anti-inflammatory and anti-fungal [7].

MDA (malondialdehyde) is a well known index of lipid oxidation reaction that is found in food, food products and cosmetics products. MDA is the well-known secondary products from lipid oxidation reaction with its structure in Fig. 2 [10].

This work aims to evaluate the antioxidant efficacy of Betel leaves extracts (fresh leaf and dried leaf) which were prepared by 7 methods such as extraction with (1) methanol, (2) ethanol, (3) hexane, (4) acid, (5) base, (6) grinding with water and (7) grinding with water followed by boiling. All extracts were performed screening test by analysis of total phenolic compound content and eugenol content. The best method for preparation of the extracts was applied in 
<smiles>C=CCc1ccc(O)c(OC)c1</smiles>

Fig. 1 Chemical structure of eugenol.<smiles>O=CCC=O</smiles>

Fig. 2 Chemical structure of MDA.

moisturizing hand cream formulations. The efficiency of Betel leaf extracts in moisture hand cream was analysed for malondialdehyde content to estimate the occurrence on lipid oxidation.

\section{Methods}

\subsection{Materials}

Chemicals: Eugenol (99\%, $\left.\mathrm{C}_{10} \mathrm{H}_{12} \mathrm{O}_{2}\right)$ was purchased from Sigma-Aldrich (Steinheim, Germany). HPLC (high performance liquid chromatography) grade methanol was purchased from Sigma-Aldrich (Steinheim, Germany). Gallic acid standard, Folin-Ciocalteu's phenol reagent, sodium carbonate, sodium acetate, sodium nitrite, sodium hydroxide, all chemical reagents were of an AR grade, purchased from Fluka and Merck. The 1,1,1,3,3-tetramethoxypropane (TMP, 99\%) and 2,4-dinitrophenylhydrazine (ARgrade) were purchased from Sigma-Aldrich (Sigma Chemical Co., USA). Hydrochloric acid ( $\mathrm{HCl}, 37 \%)$ was purchased from Merck (Merck Chemical Co., Germany). Trichloroacetic acid (AR grade) 2,6-bis (1,1-dimethylethyl)-4-methylphenol (BHT), thiourea (AR grade), 2-thiobarbituric acid (AR grade), 1-butanol, methanol and acetonitrile were purchased from Carlo Erba.

Plant samples: Betel leaf samples were purchased from Khlongtoei fresh market in Bangkok.

\subsection{Experimental Methods}

Part 1. Study on preparation of Betel extracts All plants samples were washed with tap water then dried at room temperature for a few seconds, this sample was called as fresh Betel leaf. The other leaf samples were placed into a basket and left 2 days to be dried Betel leaves samples. All samples were treated as the following methods.

Method 1 (modified from Ref. [10]).

Plant samples were chopped into small pieces, weighed 5.xxxx g and immersed in $50 \mathrm{~mL}$ of pure methanol for 48 hours. The residual plants were filtered out and the filtrate was collected. The filtrates were evaporated to dryness by rotary evaporator (Buchii rotavapor). The pure water was added to the residue and collected for future use.

Method 2 (modified from Ref. [10] ).

Plant samples were treated as Method 1, but used an ethanol in this experiment.

Method 3 (modified from Ref. [11]).

Plant samples were treated as Method 1, but used hexane in this experiment.

Method 4 (modified from Ref. [12]).

Plant samples were chopped into small pieces, weighed 5.xxxx g and mixed with $200 \mathrm{~mL}$ of $0.1 \mathrm{~N}$ sodium hydroxide solutions. Then samples were heated $60{ }^{\circ} \mathrm{C}$ for $1 \mathrm{~h}$. The residual plants were filtered out a collected filtrate. The filtrates were evaporated out as Method 1.

Method 5.

Plant leaves were chopped into small pieces, weighed 5.xxxx g and mixed with $100 \mathrm{~mL}$ of $2 \%$ hydrochloric acid solution and left for $24 \mathrm{~h}$. The residual plants were filtered out a collected filtrate. The filtrates were evaporated to dryness as Method 1.

Method 6 (modified from Ref. [13]).

Plant leaves were chopped into small pieces, weighed 5.xxxx g and mixed with $50 \mathrm{~mL}$ water. Then leaves samples were crushed and pressed to get a viscous solution. The residual plants were filtered out a collected filtrate. The filtrates were evaporated to dryness as Method 1.

Method 7 (modified from Ref. [13]).

Plant samples were chopped into small pieces, weighed 5.xxxx g and mixed with $50 \mathrm{~mL}$ water. Then 
leaves samples were heated at $60{ }^{\circ} \mathrm{C}$, crushed and pressed to get a viscous solution. The residual plants were filtered out a collected filtrate. The filtrates were evaporated to dryness as Method 1.

Part 2. Qualities evaluation on Betel extracts

Analysis of total phenolic compound content

The analysis method modified from Ref. [14], the clear filtrate $0.4 \mathrm{~mL}$ (from Part 1) was mixed with 2 $\mathrm{mL}$ of $10 \%$ Folin Ciocalteau reagent and $1.6 \mathrm{~mL}$ of $7.5 \% \mathrm{Na}_{2} \mathrm{CO}_{3}$ and kept at room temperature for 30 min. The mixing solution was recorded as an absorbance at $765 \mathrm{~nm}$ by Ultraviolet Visible Spectrophotometer (UV-VIS Shimadzu Model UV100). Total phenolic compound content was calculated as gallic acid equivalent.

Analysis of Eugenol content

The analysis method modified from Ref. [6], the clear filtrate sample $1.0 \mathrm{~mL}$ from Part 1 was cleaned up through polytetrafluoroethylene syringe filters no. $0.45 \mu \mathrm{m}$ by SPE technique. The filtrate was collected in polypropylene tubes and stored at $4{ }^{\circ} \mathrm{C}$ until analysis. The analysis was performed by HPLC system including a 1260 Quat Pump VL pumps and 1260-TCC detector, an on-line solvent vacuum degasser and manual sample injector fitted with a 20 $\mu \mathrm{L}$ injection loop. The column used was a VertiSep GES C18 column $(4.6 \mathrm{~mm} \times 250 \mathrm{~mm}, 5 \mu \mathrm{m})$. A mixture of $63 \%$ methanol and $37 \%$ water for $12 \mathrm{~min}$ at a flow rate $1.0 \mathrm{~mL} \mathrm{~min}{ }^{-1}$ were used as a mobile phase and the detection was performed at the wavelength of $280 \mathrm{~nm}$.

Part 3. Preparation on moisturizing hand cream and malondialdehyde analysis

Hand cream preparation

The cream was prepared for variation of extracted solution from Part 2, which gave the best content of total phenolic content and eugenol content as the following cream formulation, modified from Ref. [15].

F1: cream base (no extracted solution);

F2: cream base with extracted solution $(10 \% \mathrm{w} / \mathrm{w})$ from fresh Betel leaf;
F3: cream base with extracted solution $(10 \% \mathrm{w} / \mathrm{w})$ from dried Betel leaf.

Note:

Cream base formula compose of deionised water $(86.45 \% \mathrm{w} / \mathrm{w})$, Tween $20(2 \% \mathrm{w} / \mathrm{w})$, glydant $(0.5 \%$ $\mathrm{w} / \mathrm{w})$, cosmedia SP $(1 \% \mathrm{w} / \mathrm{w})$, foam seed oil $(10 \%$ $\mathrm{w} / \mathrm{w}$ ) and fragrance (2 drops) AP.

Malondialdehyde Analysis

The method for analysis of malondialdehyde content followed the work of Dourerdjou and Koner, B. C (2008) [16]. The $0.5 \mathrm{~mL}$ of filtrate was pipetted and mixed with $1.0 \mathrm{~mL}$ of $0.5 \% \mathrm{w} / \mathrm{v}$ 2-thiobarbituric acid in $20 \%$ TCA. The mixture was heated with control constant temperature at $95{ }^{\circ} \mathrm{C}$ in water bath for $30 \mathrm{~min}$, and immediately cooled in ice bath to room temperature. The mixing solution was centrifuged at $10,000 \mathrm{~g}$ for $5 \mathrm{~min}$, and the absorbance of supernatant was recorded by Ultraviolet Visible Spectrophotometer (UV-VIS Shimadzu Model UV100) at $532 \mathrm{~nm}$. The amounts of lipid peroxides were calculated as TBARS (thiobarbituric acid reactive substances) and 1,3,3-tetramethoxypropane was used as standard. The content of TBARS was calculated by comparison with the standard curve, and the level of lipid peroxides was expressed as malondialdehyde content in unit of nanogram per gram of moisture cream.

\section{Results and Discussion}

In Part 1: all treatments of leaf samples were analysed for total phenoilc content as showed in Fig. 3.

From Fig. 3 the extracts from dried Betel leaf showed the higher total phenolic content than in fresh Betel leaf. Since the dried Betel leaf was prepared by leaving the leaf samples dried at room temperature, so the water in cellulose fiber of plant was evaporated out from the cell and it makes concentrated of all substance in leaf samples. However, the $\mathrm{m} 2$ was the best method to prepare the extracts sample from plant, because the method could extract the highest total phenolic content approximate as 48,580.22 mg/100 g 


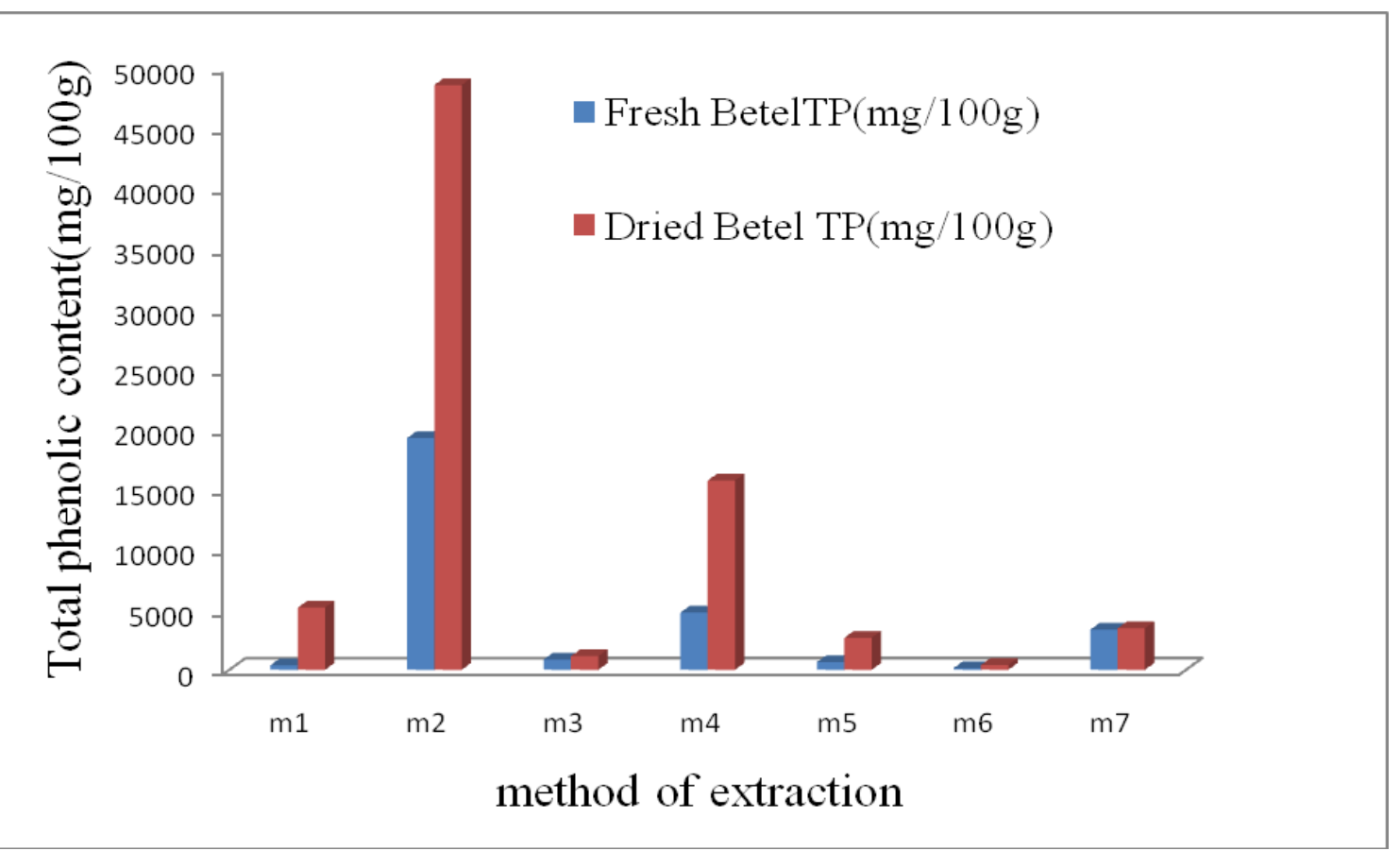

Fig. 3 Total phenolic content in Betel leaf samples.

Note:

$\mathrm{m} 1=$ extraction with methanol

$\mathrm{m} 2$ = extraction with ethanol

$\mathrm{m} 3=$ extraction with hexane

$\mathrm{m} 4$ = extraction with $0.1 \mathrm{~N} \mathrm{NaOH}$

m5 = extraction with $2 \% \mathrm{HCl}$

$\mathrm{m} 6=$ extraction with water

$\mathrm{m} 7=$ extraction with hot water

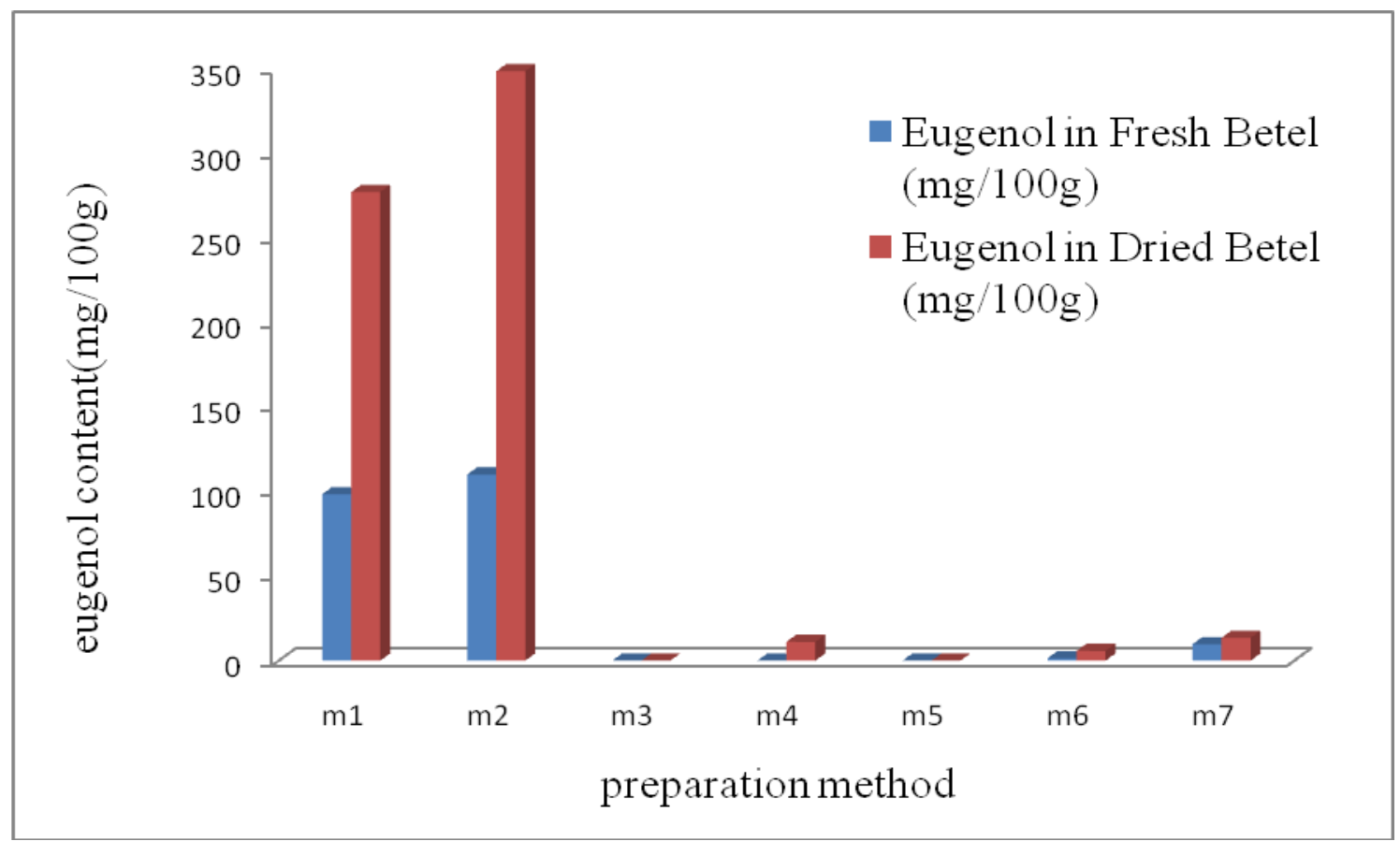

Fig. 4 Eugenol content in Betel leaf samples. 
or $48.58 \mathrm{~g} / 100 \mathrm{~g}$. This work also supports the work of Wang, C. K., et al. (1999). The $\mathrm{m} 2$ is also good and easy to practice in real life, so the Method 2 was chosen to prepare the extracts that are use in moisturizing cream. However, the content of important essential oil as eugenol is showed in Fig. 4.

After analysis of eugenol content in Betel extracts samples, it revealed that the dried Betel leaf also contained eugenol higher than fresh Betel leaf and the $\mathrm{m} 2$ showed highest eugenol content as $348.58 \pm 5.33$ $\mathrm{mg} / 100 \mathrm{~g}$ and the $\mathrm{m} 1$ presented the minor content of eugenol as $277.15 \pm 5.09 \mathrm{mg} / 100 \mathrm{~g}$. This is the reason that, eugenol is slightly soluble in water and more soluble in organic solvent [6], so this condition leached eugenol from plant more than the others method. However, using $\mathrm{m} 2$ could get an extracts with save and confirm Part 1. The moisture creams were prepared as in Part 3, total phenolic content and eugenol were measured again as presented in Table 1.
From Table 1, the formulated cream contained difference total phenolic compound content. Base cream original contained the least total phenolic content and the $\mathrm{C} 2$ (mixed with extracts from dried Betel leaf) showed the highest total phenolic compound content as $84,944.68 \pm 145.77$ or $84.95 \%$ in cream. This compound also came from the other component in cream formulation, but extracts from Betel showed additive effect in the cream. Eugenol also consisted in cream in large amount especially in C2. However, the MDA content in each cream was analysed as showed in Fig. 5.

From Fig. 5, C2 was the moisturizing with fresh Betel leaf extracts that showed lower content of malondialdehyde in cream in all range of storage time than Base cream also as C1. The C2 cream showed the least malondialdehyde content. This mean that extracts from Betel leaf could reduce the occurrence lipid oxidation in moisturizing cream.

Table 1 Properties of moisture cream.

\begin{tabular}{lll}
\hline Sample type & Total phenolic content $(\mathrm{mg} / 100 \mathrm{~g})$ & Eugenol content $(\mathrm{mg} / 100 \mathrm{~g})$ \\
\hline $\mathrm{B}$ & $317.78 \pm 25.33$ & $0.87 \pm 0.05$ \\
$\mathrm{C} 1$ & $23,403.67 \pm 120.52$ & $6.69 \pm 0.18$ \\
$\mathrm{C} 2$ & $84,944.68 \pm 145.77$ & $16.59 \pm 0.25$ \\
\hline
\end{tabular}

Note: $\mathrm{B}$ = base cream with no extracts; C1 = moisture cream with extracts from fresh Betel leaf; C2 = moisture cream with extracts from dried Betel leaf.

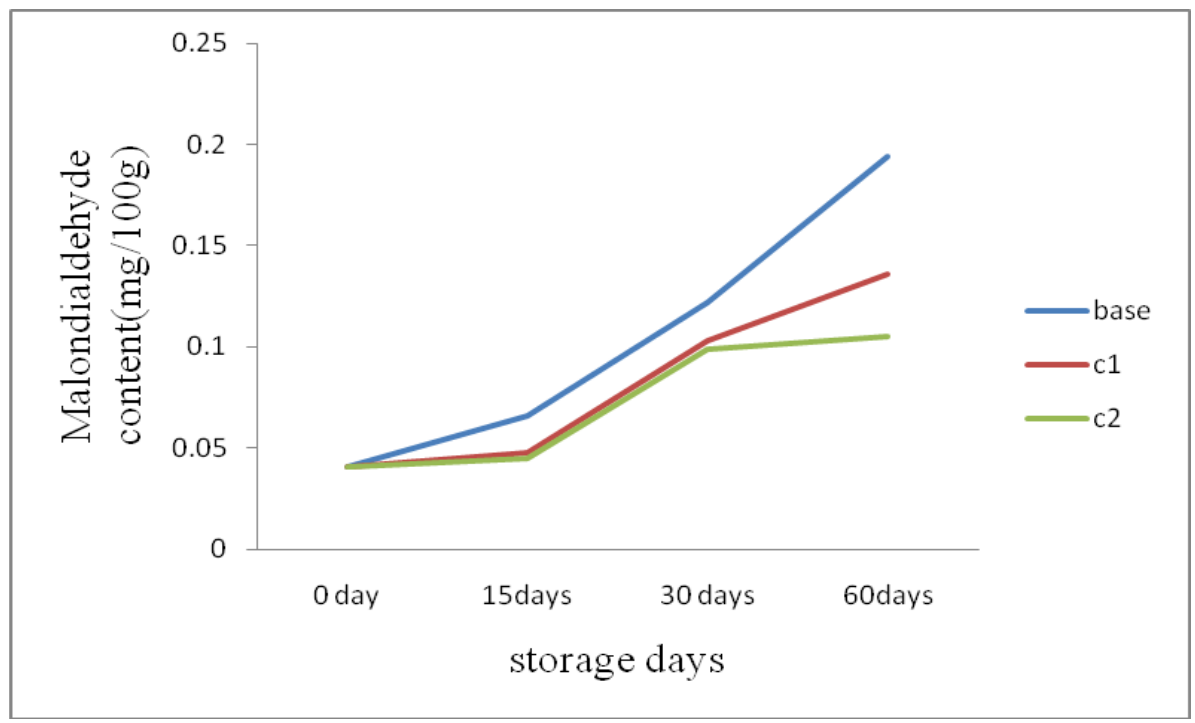

Fig. 5 MDA content in cream that storage in the range of 0-60 days. 


\section{Conclusions}

Betel leaf extracts that were prepared by 7 methods such as methanol extraction, ethanol extraction, hexane extraction, sodium extraction, hydrochloric acid extraction, grinding with water and grind and boiling in hot water revealed the different total phenolic contents including the quantity of eugenol. The dried Betel leaf contained total phenolic content and eugenol content was more than fresh Betel leaf. Method 2 that Betel leaf was extracted with ethanol showed the highest quantity of total phenolic compound and eugenol as $48.58 \mathrm{~g} / 100 \mathrm{~g}$ and 348.58 $\mathrm{mg} / 100 \mathrm{~g}$, respectively. The moisturizing cream with Betel leaf extract could reduce the lipid oxidation and dried Betel leaf is more effective on retardation than fresh Betel leaf. Both fresh and dried Betel extracts revealed the efficiency as natural antioxidant in cream.

\section{Acknowledgments}

The authors are grateful to the Strategic Wisdom and Research Institute of Srinakharinwirot University for supporting the money from Annual government statement of expenditure in 2016.

\section{References}

[1] Kumar, N., Misra, P., Dube, A., Bhattacharya, S., Dikshit, M., and Ranade, S. 2010. "Piper Betle Linn. A Maligned Pan-Asiatic Plant with an Array of Pharmacological Activities and Prospects for Drug Discovery.” Current Science 99: 922-32.

[2] Chu, N. S. 2001. "Effects of Betel Chewing on the Central and Autonomic Nervous Systems.” J. Biomed. Sci. 8 (3): 229-36.

[3] Pushpavalli, G., Veeramani, C., and Pugalendi, K. V. 2008. "Influence of Piper Betel on Hepatic Marker Enzymes and Tissue Antioxidant Status in D-Galactosamine-Induced Hepatotoxic Rats.” J. of Basic and Clinical Physiology and Pharmacology 19: 131-50.

[4] Baratta, M. T., Dorman, H. J. D., Deans, S. G., Figueiredo, A. C., Barroso, J. G., and Ruberto, G. 1998. "Antimicrobial and Antioxidant Properties of Some Commercials.” Flavour Frag J. 13: 235-44.

[5] Lee, H., Cheng, S., and Chang, S. 2005. “Antifungal Property of the Essential Oils and Their Constituents from Cinnamon Osmophloeum Leaf against Tree
Pathogenic Fungi.” J. Food Agric. 85 (12): 2047-53.

[6] Schulz, K., Schlenz, K., Malt, S., Metasch, R., Romhild, W., Drebler, J., and Dirk, W. L. 2008. "Headspace Solid-Phase Microextraction-Gaschromatography-Mass Spectrometry for the Quantitative Determination of the Characteristic Flavouring Agent Eugenol in Serum Samples after Enzymatic Cleavage to Validate Post-Offence Alcohol Drinking Claims.” J. Chromatography A 1211: 113-9.

[7] Gurupadayya, B. M., Sruthi, B. Y. K., Venkata, S. K., and Kumar, T. N. 2014. "Development and Validation of GC Method for the Estimation of Eugenol in Clove Extract." J. Pharmacy and Pharmaceutical Sciences 6: 473-6.

[8] Geng, Y. L., Liu, J. H., Lv, R. M., Yuan, J. P., Lin, Y. L., and Wang, X. 2007. “An Efficient Method for Extraction, Separation and Purification of Eugenol from Eugenia Caryophyllata by Supercritical Fluid Extraction and High-Speed Counter-Current Chromatography." J. Separation and Purification Technology 57: 237-41.

[9] Gursale, A., Dighe, V., and Parekh, G. 2010. "Simultaneous Quantitative Determination of Cinnamaldehyde and Methyl Eugenol from Stem Bark of Cinnamomum zeylanicum Blume Using RP-HPLC.” J. Chromatographic Science 48: 59-62.

[10] Inam, F., Deo, S., and Narkhede, N. 2014. "HPLC-UV Method Development and Quantification of Eugenol from Methanolic Extracts of Some Spices.” J. Chemical and Physical Sciences 2014: 96-102.

[11] Hahn, C. N., and Burkett, J. R. 2013. “Optimizing Eugenol Extraction Conditions from Fresh and Dried Samples of Holy Basil (Ocimum Sanctum)." J. Plant Science and Research 3 (5): 28-31.

[12] Botsoglou, N. A., Fletouris, D. J., and Papageorgiou, G. E. 1994. "Rapid, Sensitive, and Pecific Thiobarbituric Acid Method for Measuring Lipid Peroxidation in Animal Tissue, Food, and Feedstuff Samples.” J. Agric. Food Chem. 42: 1931-7.

[13] Kima, S. J., Murthy, H. N., Hahn, E. J., Lee, H. L., and Paek, K. Y. 2007. "Parameters Affecting the Extraction of Ginsenosides from the Adventitious Roots of Ginseng (Panax Ginseng C.A. Meyer).” Separation and Purification Technol. 56: 401-6.

[14] Yuan, Y. V., and Walsh, N. A. 2006. "Antioxidant and Antiproliferative Activities of Extracts from a Variety of Edible Seaweeds." Food and Chemical Toxicol. 44: 1144-50.

[15] Sharma, P. P. 2008. Cosmetics-Formulation, Manufacturing and Quality Control. Vandana Publication PVT. LTD.

[16] Dourerdjou, P., and Koner, B. C. 2008. "Effect of Different Cooking Vessels on Heat-Induced Lipid Peroxidation of Different Edible Oils.” Journal of Food Biochemistr. 32: 740-51. 